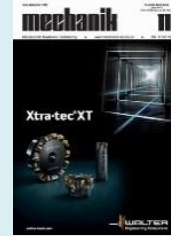

Author: Przemysław Podulka

Title of article: „Analiza rozmieszczenia kieszeni olejowych w pomiarach struktury geometrycznej powierzchni” (“Analysis of dimples distribution in surface topography measurements")

Mechanik, Vol. 91, No. 11 (2018): pages 984-987

DOI: https://doi.org/10.17814/mechanik.2018.11.176

\title{
Analysis of dimples distribution in surface topography measurements
}

\author{
Analiza rozmieszczenia kieszeni olejowych \\ w pomiarach struktury geometrycznej powierzchni
}

Przemysław Podulka *

In this paper the influence of distribution of oil pockets on areal form removal in surface topography measurement was taken into consideration. Surface topography of plateauhoned cylinder liners with burnished oil pockets was analysed. The effect of dimples distribution on surface topography parameters (from ISO 25178 standard) after form removal by commonly used algorithms (cylinder fitted by the least square method, polynomials of nth degree, robust Gaussian filter) and/or other procedures (plateau-part filtering method, digital extraction of valleys) was taken into account.

KEYWORDS: surface topography, cylinder liners, oil pockets, dimples distribution

Analysis of the surface topography provides detailed information on the surfaces cooperating with each other. Typically, the stereometric properties of the surface are analysed after removing its outline shape and waviness (resulting from errors in the part being made) [1]. To date, many scientific papers and articles have concerned the elimination of irrelevant frequency components by using digital filtration. There are many filtration algorithms, but few works have been done in terms of the selection of the reference surface and its impact on surface stereometry parameters. It is recommended that the reference element be selected depending on the type of surface being analysed [2].

The inaccuracy of surface measurements - in addition to the measured surface, apparatus and measurement procedure - is influenced by incorrect digital filtration and the interpretation of measurement results [3-5]. In turn, problems resulting from improperly performed elimination of the shape outline are important especially in the case of the analysis of surfaces with layered functional properties (e.g. cylinder surfaces of combustion engines) [6].

To eliminate the shape contour, the cylinder (as a geometric element) [7, 8], polynomials [9, 10], digital filters (morphological [11], error-proof [12-14]) and other methods [15] were used. Various modifications of digital filters were also introduced to the procedures, such as: filtration of only the surface plateau-part [16] or the algorithm based on the digital filling of the lubricating pockets [17]. A broad overview of measurement methods (and errors) in the analysis of the surface topography is presented in [18-21]. The elimination

\footnotetext{
* PhD, Przemysław Podulka (p.podulka@prz.edu.pl) - Department of Manufacturing Processes and Production Engineering, The Faculty of Mechanical Engineering and Aeronautics, Rzeszow University of Technology
}

of the shape of surfaces containing wide depressions is a serious problem, especially when these pockets are close to the edge of the analysed detail.

The author has attempted to determine the effect of the arrangement of oil pockets on the removal of the shape outline of the cylinder surface of internal combustion engines.

\section{Analysed surfaces and measurement methods}

The analysed elements were the plateau-honed cylinder surfaces of internal combustion engines, with additional burnished oil (lubrication) pockets. The depth of the pocket was from 30 to $120 \mu \mathrm{m}$, and the width - from 0.4 to $1.2 \mathrm{~mm}$. The research involved the influence of the selection of the reference surface on the surface stereometry parameters (according to ISO 25178). The measurement equipment were: Talysurf $\mathrm{CCl}$ Lite white light interferometer (with a vertical resolution of $0.1 \mathrm{~nm}$ ) and Talyscan 150 contact profilometer (with a measuring tip with a nominal radius of 2 $\mu \mathrm{m})$. Over 20 measured surfaces and over 20 surfaces with digitally added lubrication pockets were analysed. The maximum surface size was $5 \mathrm{~mm} \times 5 \mathrm{~mm}$ (some of the surface elements were analysed in separate profiles and details), and the sampling step - from 3.27 $\mu \mathrm{m}$ (optical measurement) to $5 \mu \mathrm{m}$ (contact measurement). The elimination of the shape outline was made using:

- cylinder fitting algorithm using the least squares ( $C^{\text {LSFM }}$ ) method,

- polynomials of the second, third and fourth degrees $\left(P^{2}\right.$, $\left.\mathrm{P}^{3}, \mathrm{P}^{4}\right)$,

- digital filter (Gaussian regression filter - $F^{\mathrm{GR}}$ ).

The effects of using algorithms depending on the distance (distance) of pits (pockets) in relation to each other $\left(\mathrm{V}^{\mathrm{DIS}}\right)$ and from the edge of the analysed surface $\left(\mathrm{V}^{\mathrm{ED}}\right)$ and the width (size) of the pocket $\left(\mathrm{V}^{\mathrm{S}}\right)$ were investigated; the cutoff $\left(\mathrm{F}^{\mathrm{CO}}\right)$ length of digital filter was also taken into account.

\section{Research results and their analysis}

The analysis of the isometric view presented in fig. 1 shows that the use of the alignment algorithm in the shape of a cylinder (a), as well as the use of second degree polynomial (c) and fourth (e) may not ensure complete removal of the curvature; the lack of a properly selected reference surface can be observed on the extracted profiles (b, d and f). Increasing the degree of polynomial caused an increase in distortion of oil pockets. 


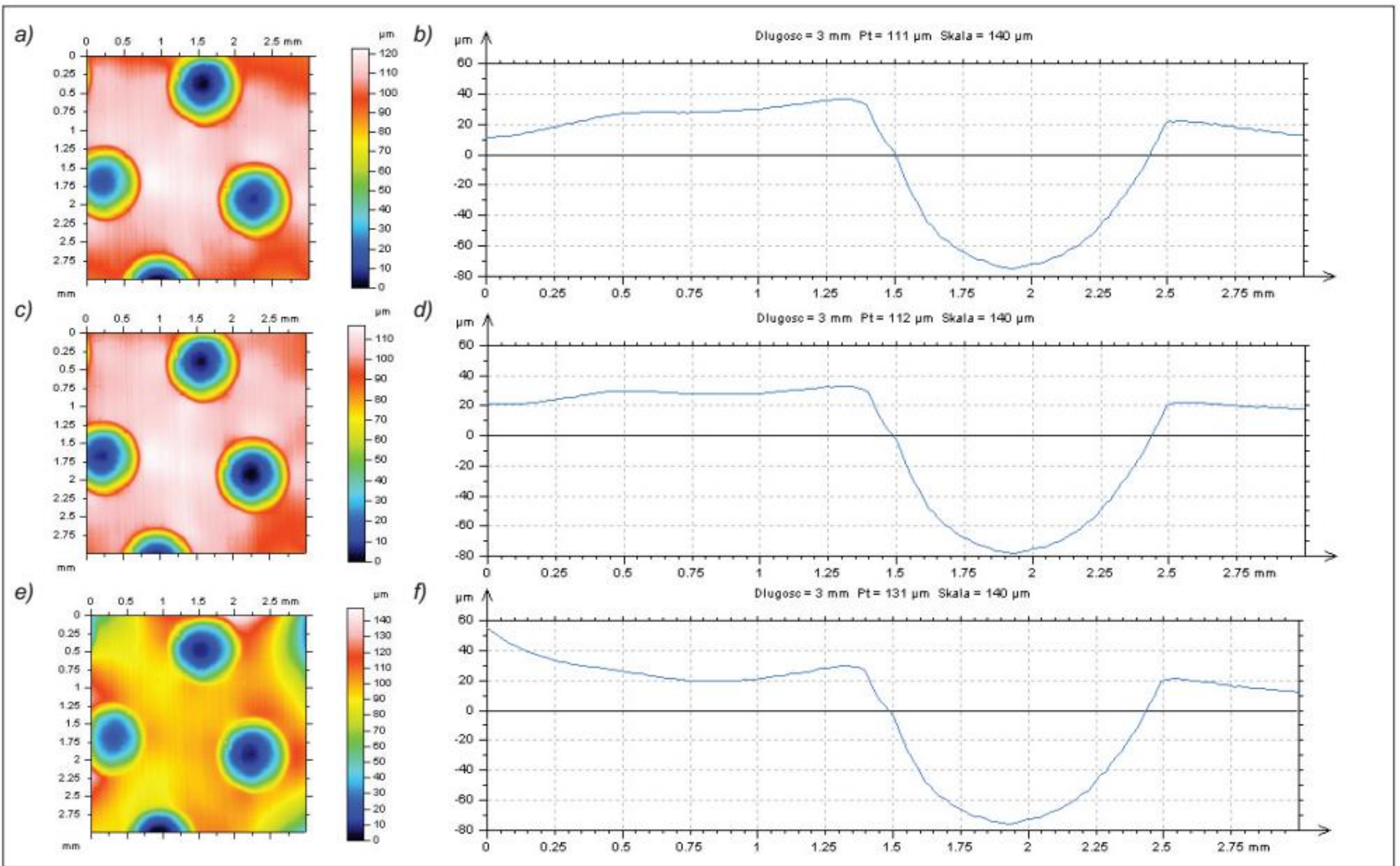

Fig. 1. Cylinder surfaces after elimination of the form using $C^{\text {LSFM }}(a), \mathrm{P}^{2}(c)$ or $\mathrm{P}^{4}(e)$ and exemplary profiles $(b, d, f)$

If $\mathrm{V}^{\mathrm{DIS}}<1 \mathrm{~mm}$ and/or $\mathrm{V}^{\mathrm{ED}}<0.5 \mathrm{~mm}$, then the use of polynomials (even the second degree) could cause distortion of the reference surface and the lubrication pockets themselves.

A robust Gauss regression filter is often used to eliminate the shape of a surface with layered functional properties. It is characterised by a much higher (in comparison with the regular Gauss filter) resistance to irregular elements (single pin-like tops, depressions).

If $\mathrm{V}^{\mathrm{ED}}<\mathrm{F}^{\mathrm{CO}}$, then the distortion of the lubrication cavity (also part of the surface between the edge and the lubrication pocket) increased; the location of the reference surface was determined incorrectly. Often, the lubricating pockets were not deformed, but only the area between the recess and the edge of the surface; in the case when the lubricating cavity was directly at/on the edge of the analysed detail, the distortion reached the maximum values (fig. 2a). Changes could also be observed in the areas adjacent to the lubrication recesses, but not close to $\left(\mathrm{V}^{\mathrm{ED}}>1 \mathrm{~mm}\right)$ edges of the analysed surface (fig. $3 a$ and fig. $3 b$ ). Distortion of recesses can negatively affect the parameters of surface stereometry: the value of the maximum height of surface peak $S p$ can be more than doubled, the maximum surface height $S z$ can increase by over $30 \%$, the reduced height of spikes can be overstated by over three times, and the reduced depth of the valleys $S_{\mathrm{vk}}$ can decrease by approx. $14 \%$ (fig. 2).

If $\mathrm{V}^{\mathrm{DSS}}<\mathrm{V}^{\mathrm{S}}$, then the distortion of the area between the pits increased, even when $\mathrm{F}^{\mathrm{CO}}>\mathrm{V}^{\mathrm{S}}$ (fig. 4b). If $\mathrm{V}^{\mathrm{S}}<\mathrm{V}^{\mathrm{DIS}}$ and $\mathrm{V}^{\mathrm{S}}<\mathrm{F}^{\mathrm{CO}}$, then the distortion of the lubricating cavities and their adjacent areas (also areas between the pockets or between the pockets and the edge of the analysed detail) did not occur or occurred to a minimal extent (fig. 4a).

Analysing the details extracted from the surface (fig. 5) after elimination of the shape/waviness, the following conclusions were drawn. The polynomial approximation $\left(\mathrm{P}^{2}\right.$,
$\mathrm{P}^{3}$ or $\left.\mathrm{P}^{4}\right)$ caused incorrect determination of the reference surface position if $\mathrm{V}^{\mathrm{DIS}}<1 \mathrm{~mm}$; often the deformation also increased at $\mathrm{V}^{\mathrm{ED}}<0.5 \mathrm{~mm}$.

Thanks to $\mathrm{F}^{\mathrm{GR}}$, the smallest values of the analysed parameters of surface stereometry were obtained. The average square deviation of the $S q$ surface was twice smaller after using digital filtration compared to polynomials, the values of $S p$ and $S z$ parameters decreased by over $40 \%$, and the $S_{\mathrm{pk}}$ parameter decreased by over $65 \%$. The use of digital filtration is necessary due to the reduction of errors in the determination of surface stereometry parameters.

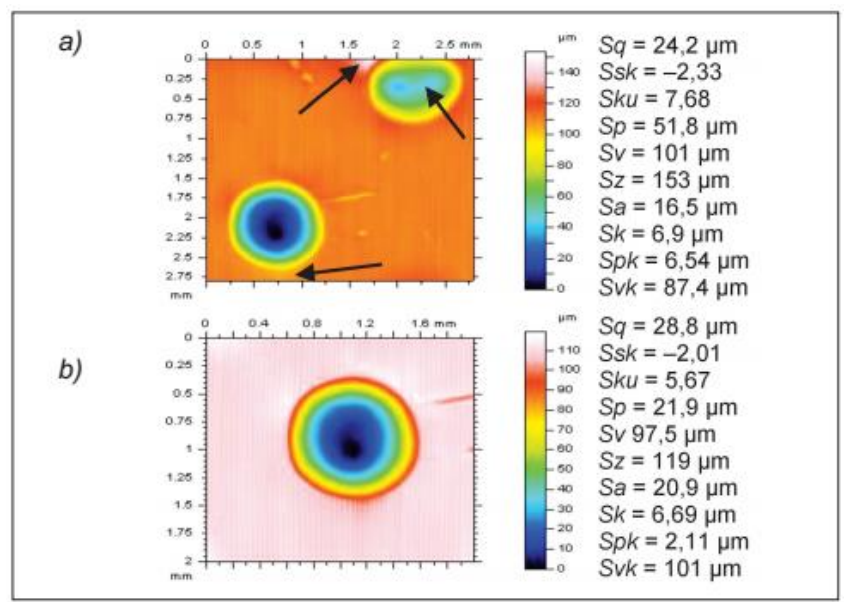

Fig. 2. Cylinder surfaces (and their surface topography parameters respectively) after removing the shape outline with $\mathrm{F}^{\mathrm{GR}}\left(\mathrm{F}^{\mathrm{CO}}=0.8\right.$ $\mathrm{mm}$ ), containing lubrication recesses of various positions: pockets arranged close/on the edge of the analysed detail (a) and centrally (b) 
a)

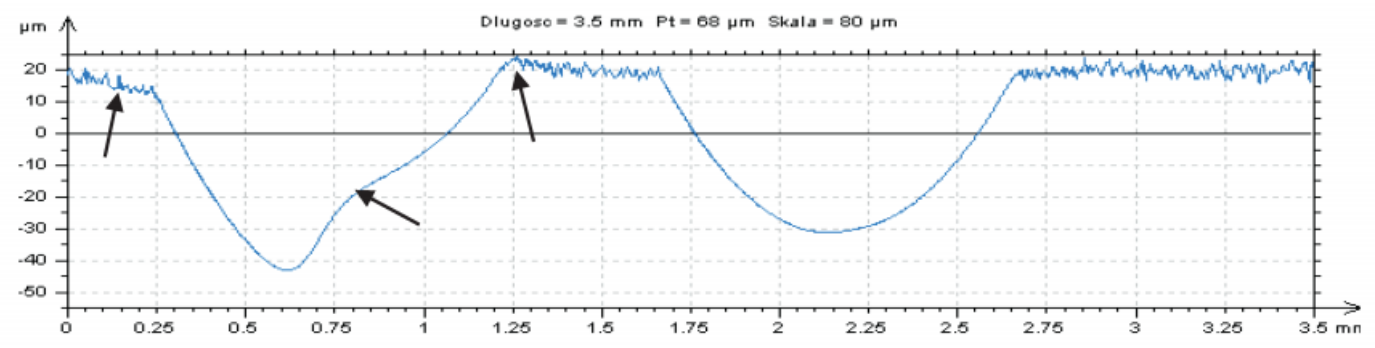

b)

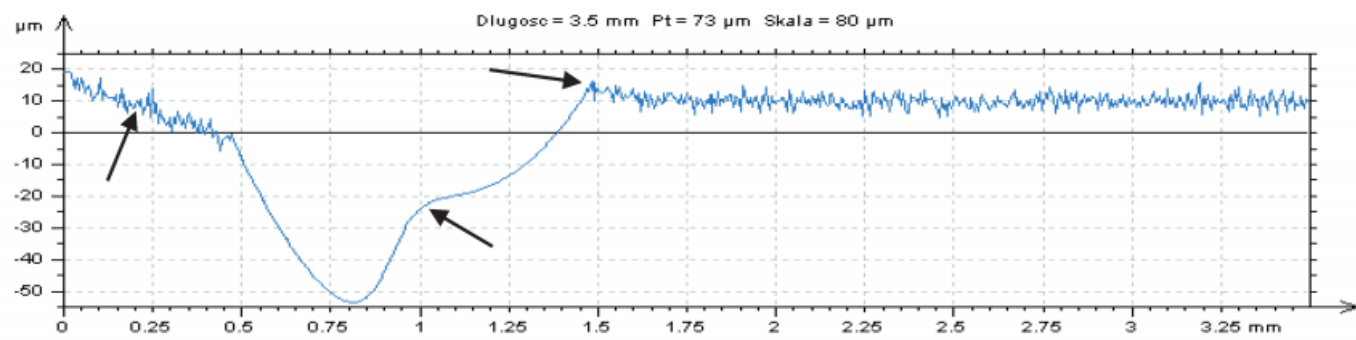

c)

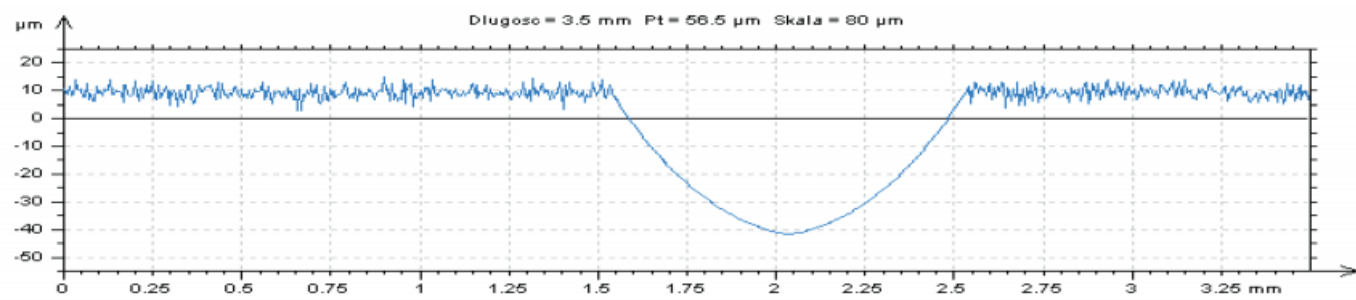

Fig. 3. Surface profiles after application of $\mathrm{F}^{\mathrm{GR}}\left(\mathrm{F}^{\mathrm{CO}}=0.8 \mathrm{~mm}\right)$ : a) $\left.\left.\mathrm{V}^{\mathrm{ED}}=0.25 \mathrm{~mm}, b\right) \mathrm{V}^{\mathrm{ED}}=0.5 \mathrm{~mm}, c\right) \mathrm{V}^{\mathrm{ED}}=1 \mathrm{~mm}$

a)

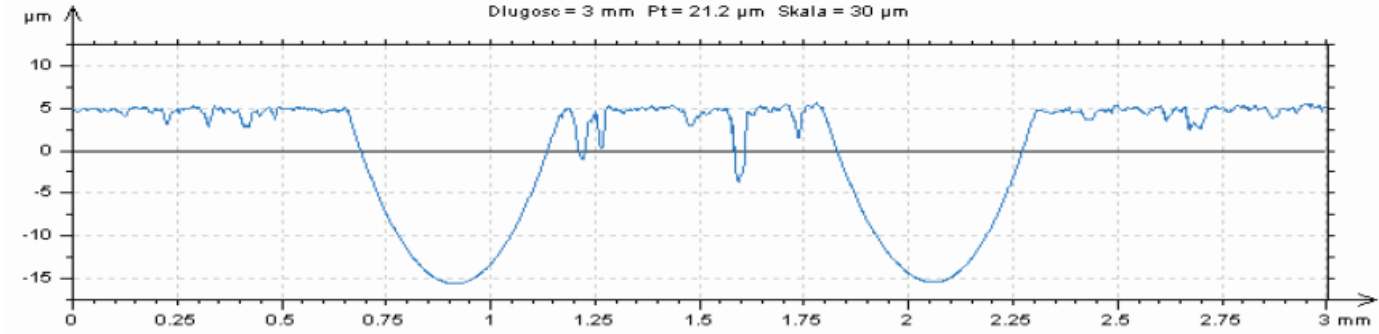

b)

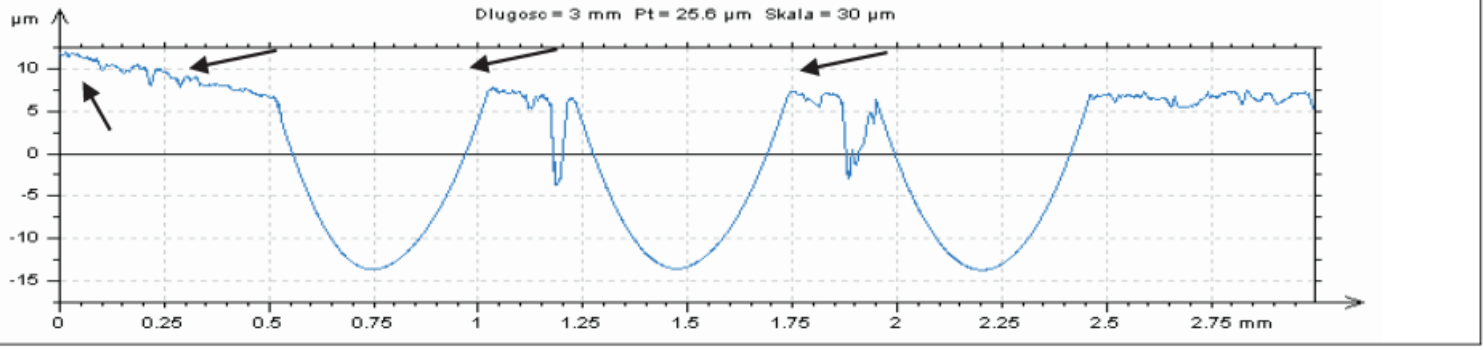

Fig. 4. Surface profiles after digital filtration: a) $\left.\mathrm{V}^{\mathrm{DIS}}=0.6 \mathrm{~mm}, b\right) \mathrm{V}^{\mathrm{DIS}}=0.25 \mathrm{~mm}$

Errors in the determination of surface stereometry parameters can be caused by the digital distortion of the analysed lubrication recesses during the elimination of the shape outline.

If $\mathrm{V}^{\mathrm{S}}>0.5 \mathrm{~mm}$, it is necessary to use a digital filter $\left(\mathrm{F}^{\mathrm{GR}}\right)$ instead of cylindrical matching algorithms or polynomial approximation (second or higher degree).

Errors in the surface topography features analysis (parameter value determination) can be minimised by reducing the digital distortion of the oil pockets. Incorrect selection of the reference surface in turn influences the determination of surface stereometry parameters and can cause that correctly made elements will be considered as deficiencies. If the surface contains lubrication recesses of $0.5 \mathrm{~mm}<\mathrm{V}^{\mathrm{S}}<\mathrm{F}^{\mathrm{CO}}$, then the use of error-proof filters allows correct elimination of the shape contour (you can get the correct location of the reference surface in places where oil pockets exist). However, the use of $\mathrm{F}^{\mathrm{CO}}>0.8 \mathrm{~mm}$ will not always completely eliminate the shape error.

For surfaces containing lubricating cavities with $\mathrm{a} \mathrm{V}^{\mathrm{S}}>0.8 \mathrm{~mm}$ it is recommended to use alternative procedures (e.g. an algorithm based only on filtration of the surface bearing part or the procedure of the digital filling of the lubricating pockets). 


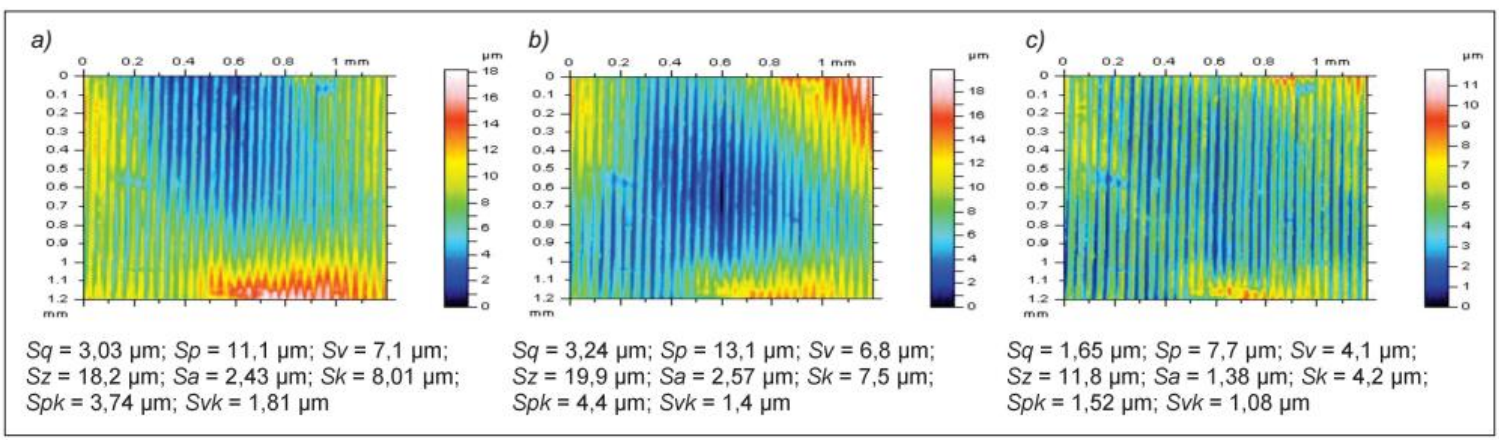

Fig. 5. Details separated from the surface (along with amplitude parameters) after removing the shape with: a) $\left.\mathrm{P}^{2}, b\right) \mathrm{P}^{4}$, c) $\mathrm{F}^{\mathrm{GR}}\left(\mathrm{F}^{\mathrm{CO}}=0.8 \mathrm{~mm}\right)$

\section{Conclusions}

The analysis of the results of the research presented in the article allowed to draw the following conclusions:

- Application of the cylinder alignment algorithm with the least squares method did not allow proper elimination of the shape error, when the $\mathrm{V}^{S}>0.5 \mathrm{~mm}$ - in the case of selecting the reference surface, in this case polynomial approximation or digital filtration should be used.

- The use of a second degree polynomial approximation allows correct selection of the reference surface, if the $\mathrm{V}^{\mathrm{S}}<$ $0.5 \mathrm{~mm}, \mathrm{~V}^{\mathrm{DIS}}>1 \mathrm{~mm}$ and $\mathrm{V}^{\mathrm{ED}}>0.5 \mathrm{~mm}$; otherwise, distortions of lubrication cavities and areas between the pockets and the edges of the analysed detail increased then the use of digital filtration is recommended.

- Gauss regression-proof filtration introduced distortion of the lubrication pockets (also parts of the surfaces located between the edge and the hollow) when $\mathrm{V}^{\mathrm{ED}}<\mathrm{F}^{\mathrm{CO}}$. Irregularities in the determination of the reference surface could also be observed in the areas of the detail adjacent to the lubricating pockets, located above $1 \mathrm{~mm}$ from the edge of the surface $\left(\mathrm{V}^{\mathrm{ED}}>1 \mathrm{~mm}\right)$.

- When applying digital filtering (while maintaining the condition $\mathrm{V}^{\mathrm{DIS}}<\mathrm{V}^{\mathrm{S}}$ ) distortions between the pits increased (even for $\mathrm{F}^{\mathrm{CO}}>\mathrm{V}^{\mathrm{S}}$ ). If $\mathrm{V}^{\mathrm{S}}<\mathrm{V}^{\mathrm{DIS}}$ and $\mathrm{V}^{\mathrm{S}}<\mathrm{F}^{\mathrm{CO}}$, the distortion of lubricating pockets and their adjacent areas (also areas between pockets and/or between pockets and the edge of the analysed surface) did not occur or were negligible.

- For the elimination of the shape contour of cylindrical surfaces containing lubrication recesses (where $\mathrm{V}^{\mathrm{S}}>0.5$ $\mathrm{mm}$ ), it is recommended to use digital filtration instead of cylinders or polynomial matching algorithms (also the second degree).

- In the case of cylinder surfaces after plateau-honing process, containing wide recesses $\left(\mathrm{V}^{\mathrm{S}}>0.5 \mathrm{~mm}\right)$, to minimize the distortion of the lubrication pockets (when eliminating shape errors), the filtration procedure of only the surface bearing part or digital cavity filling can be used alternatively.

- In order to eliminate errors in the shape of the surface of cylinders containing wide recesses, it is recommended to use a filter resistant to Gaussian regression errors. One should also pay attention to the location of the reference surface in the places where the lubrication pockets are located. If the $\mathrm{V}^{\mathrm{S}}>0.8 \mathrm{~mm}$, the digital filter may not ensure correct determination of the reference surface position alternative digital procedures should be used (filtration only of the surface bearing part or an algorithm with digitally filled lubrication pockets).

\section{REFERENCES}

1. Leach R. "Characterisation of areal surface texture". Berlin: SpringerVerlag, 2013.

2. Stout K.J., Sullivan P.J., Dong W.P., Mainsah E., Luo N., Mathia T., Zahouani $\mathrm{H}$. "The development of methods for the characterisation of roughness in three dimensions". Publication EUR 15178 EN Commission of the European Communities, 1993.
3. Blunt L., Jiang X. "Advanced Techniques for Assessment of Surface Topography'. London: Kogan Pages, 2003.

4. Whitehouse D.J. "Handbook of Surface Metrology". Bristol and Philadelphia: Inst. of Physics, 1994.

5. Thomas T.R. "Rough Surfaces. Second Edition". London: Imperial College Press, 1999.

6. Podulka P., Dobrzański P., Pawlus P., Lenart A. "The effect of reference plane on values of areal surface topography parameters from cylindrical elements". Metrol. Meas. Syst. 21, 2 (2014): pp. 247-256.

7. Forbes A.B. "Least squares best fit geometric elements". NLP report DITC 40 (89), Teddington, UK, 1989.

8. Podulka P. "Selection of reference plane by the least squares fitting methods". Adv. Sci. Technol. Res. J. 30, 10 (2016): pp. 164-175.

9. Sullivan P.J. "Surface topography filtering". Metrology and Properties of Engineering Surfaces. Springer, 2001.

10. De Chiffre L., Lonardo P., Trumpold H., Lucca D.A., Goch G., Brown C.A., Raja J., Hansen H.N. "Quantitative Characterisation of Surface Texture". CIRP Ann. Manuf. Techn. 49, 2 (2000): pp. 635-642, 644652.

11. Lou S., Jiang X., Scott P.J. "Applications of morphological operations in surface metrology and dimensional metrology". J. Phys. Conf. Ser. 483 (2014): pp. 012020.

12. Brinkman S., Bodschwinna H. "Advanced Gaussian filters". Advanced Techniques for Assessment Surface Topography. London and Sterling: Kogan Page Science, 2003, pp. 62-89.

13. Brinkman S., Bodschwinna H., Lemke H.-W. "Development of a robust Gaussian regression filter for three-dimensional surface analysis". $X$ International Colloquium on Surfaces. Chemnitz, Germany, 2000, pp. 122-131.

14. Dobrzański P., Pawlus P. "A study of filtering techniques for areal surface topography assessment". Proc. Inst. Mech. Eng. B J. Eng. Manuf. 225, 11 (2011): s. 2096-2107.

15. Muralikrishnan B., Raja J. "Computational surface and roundness metrology". Springer, 2009

16. Pawlus P., Dobrzański P., Podulka P. „Modyfikacja filtru cyfrowego w odniesieniu do powierzchni zawierających szerokie wgłębienia". Mechanik. 8-9 (2014): pp. 291-298.

17. Podulka P., Pawlus P., Dobrzański P. „Wyodrębnianie wgłębień na powierzchniach cylindrycznych". Mechanik. 11 (2016): pp. 1700-1701.

18. Wieczorowski M., Pawlus P., Mathia T. "The errors of stylus methods in surface topography measurements". Szczecin: ZAPOL, 2014.

19. Wieczorowski M. „Wykorzystanie analizy topograficznej w pomiarach nierówności powierzchni". Poznań: Wydawnictwo Politechniki Poznańskiej, 2009

20. Podulka P. "Problem of selection of reference plane with deep and wide valleys analysis". J. Phys.: Conf. Ser. 1065 (2018) 072017.

21. Mathia T.G., Pawlus P., Wieczorowski M. "Recent trends in surface metrology". Wear. 271, 3-4 (2011): pp. 494-508.

Translation of scientific articles, their computer composition and publishing them on the website www.mechanik.media.p by original articles in Polish is a task financed from the funds of the Ministry of Science and Higher Education designated for dissemination of science.

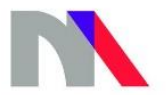
and Higher Education 